\title{
Immunohistochemical detection of micrometastasis and disseminated tumor cells in microscopically tumor free lymph nodes H Adams* and S Dirnhofer
}

Address: Institut für Pathologie, Universität Basel, Switzerland

* Corresponding author

from 35te Tagung der Pathologen am Oberrhein/35th Meeting of Pathologists of the Upper Rhine Region (PATOR) The Institute of Pathology, University Hospital Freiburg, Germany. I July 2006

Published: 14 March 2007

Diagnostic Pathology 2007, 2(Suppl I):S2 doi:I0.I I86/I746-I596-2-SI-S2

(C) 2007 Adams and Dirnhofer; licensee BioMed Central Ltd.

Frequency and clinical relevance of micrometastasis (pN1 $\mathrm{mi})$ and disseminated tumor cells (pNOi+) in carcinoma patients are controversially debated or unclear. Thus we immunohistochemically examined the lymph nodes of 422 pNo classified patients (conventional light microscopy) between November 2004 and March 2006, using the cytokeratin (CK)-22 antibody.

In 13 cases (3\%), we found previously undetected micrometatasis (pN1 mi) and 84 cases $(20 \%)$ were positive for disseminated tumor cells, discovered by immunohistochemistry.

In all cases in which micrometastasis was found, it was only present in one of the lymph nodes examined, whereas isolated tumor cells were found in up to five nodes from one patient. Cases with such findings are mainly breast and colon cancers ( $\mathrm{pNO} \mathrm{i}+$ in colorectal carcinomas: $\mathrm{n}=39$, breast: $\mathrm{n}=25$, other entities together: $\mathrm{n}$ = 19; micrometastasis ( $\mathrm{pN} 1 \mathrm{mi})$ : colorectal carcinoma: $\mathrm{n}$ $=3$, breast: $n=5$, other entities together: $n=5$ ).

While the meaning of micrometastasis in axillary lymph nodes is undebated and thus integrated in the TNM system, the prognostic value of this finding for other entities remains unclear. However, the WHO suggests a classification scheme for these.

We will now start to collect follow-up results for all patients in this study to conclude how to deal with these findings in future. 